\title{
Different treatment modalities and outcomes in cesarean scar pregnancy: a retrospective analysis of 31 cases in a university hospital
}

\author{
Adnan Orhan, Işıl Kasapoğlu, Bilge Çetinkaya Demir, \\ Kemal Özerkan, Nergis Duzok, Gürkan Uncu \\ Uludag University Hospital, Department of Obstetrics and Gynecology, Gorukle Campus, Bursa, Turkey
}

\begin{abstract}
Objectives: There is no standardized treatment modality or a generally accepted guideline in cesarean scar pregnancy (CSP) treatment. The aim of this study is to retrospectively evaluate the outcomes of the different treatment modalities used in CSP treatment.

Material and methods: 31 CSP patients retrospectively evaluated between May 2011 and February at Uludag University Hospital in Bursa, Turkey included in the study. A graphical flowchart according to the treatment modalities and timeline graphics of the patients were used. Main outcome measures were recurrent CSPs and healthy pregnancies in clinical follow-up after a successful CSP treatment.

Results: 31 CSP patients were treated with six different treatment modalities in our series. Recurrent CSP was diagnosed in three patients after a successful CSP treatment. All of these recurrent CSPs were treated with D/C procedure in their first CSP. Six patients conceived again in clinical follow-up after successful treatment of CSP.

Conclusions: CSP is a serious maternal complication that risks the mother's life, and this problem is growing because of the increased cesarean rates. Invasive procedures applied to the uterus in CSP treatment may cause recurrent CSP in the next pregnancy of the patient. When considering the treatment options of the CSP, minimally invasive treatment modalities and the subsequent gestation of the patient should be taken into account.
\end{abstract}

Key words: Cesarean scar pregnancy; treatment modalities; Morbidly adherent placenta

Ginekologia Polska 2019; 90, 6: 291-307

\section{INTRODUCTION}

Cesarean rates have shown a significant increase in the last two decades although all the medical precautions are taken all over the World [1]. Parallel to this increase, cesarean rates in Turkey unprecedentedly escalated from 21 percent in 2002 to 53 percent in 2015 [2]. Although these rates are higher in Turkey, cesarean rates were 28 percent in the upper-income group, 32 percent in the upper-middle-income group and 17 percent in all over the world according to the WHO health statistics between 2007 and 2014 [3]. As the primary cesarean rates increase, the complications in the subsequent pregnancies also increase. Among these complications, cesarean scar pregnancies (CSP) and placental invasion anomalies are the most important ones because of the catastrophic pregnancy outcomes $[4,5]$.
Cesarean scar pregnancy was first described in 1978 [6]. Although it has been mentioned with many different names, CSP has become the most common definition in recent years $[7,8]$. There was a significant increase in CSPs due to the rise in the rates of cesarean section [9]. The probability of CSP in a pregnant patient who had a previous cesarean section is approximately 1 in 2000 pregnancies [10]. Although it is mentioned in the literature that the diagnosis of CSP is problematic, it can be diagnosed if attention is paid to implantation localization [11]. The difficult part is to make a treatment plan on a subject where the treatment is not standardized, and there are no generally accepted guidelines worldwide. Patients who demand the continuation of their pregnancy, there is a dangerous process that goes from morbidly adherent placenta (MAP) to maternal mortality [12]. 
In this study, a retrospective analysis of thirty-one cesarean scar pregnancies which we treated in the last six years, has been done in our university hospital. The outcomes of different CSP treatment modalities and normal pregnancies or recurrent after the treatments in clinical follow-up were analyzed.

\section{MATERIALS AND METHODS}

This article includes retrospective data from 31 CSP patients who were examined in Uludag University Hospital Bursa, Turkey between May 2011 and February 2017. Weekly or monthly monitored $\beta$-HCG (human chorionic gonadotropin) levels in patient records were analyzed, and timeline graphics of each patient were prepared. Transvaginal ultrasonographic evaluations (Philips ClearVue 650, Philips Healthcare, The Netherlands) during diagnosis, treatment, and follow-up were taken from the patient files. The presence or absence of fetal heart activity (FHA) was also extracted from the patient records.

Since there is no standard definition for CSP diagnosis, the presence of all clinical findings which were described below is used to diagnose CSP [4].

1. An empty uterine cavity and a closed and empty cervical canal.

2. The placenta \pm a gestational sac embedded in the hysterotomy scar

3. A rich vascular pattern in the area of the cesarean scar with a positive pregnancy test

4. Absent myometrial layer between the gestational sac and the bladder

5. A triangular or rounded gestational sac that fills the niche of the scar

6. The presence of embryonic pole \pm yolk sac with or without heart activity.

Treatment options are offered to each patient after the CSP was diagnosed. Details of the advantages and complications of each treatment are provided. Their clinician decided assignment of the women to one of the six treatment methods. The treatment decision is reported to the patient, and the patient's informed written consent is obtained. Patients are monitored with the pelvic examination, B-HCG test, and ultrasonography in our outpatient clinic once in a week or month regularly for up to 2 years after the treatment. Women were reevaluated by ultrasonography for isthmocele before their subsequent pregnancy.

There were six primary treatment modalities which were used in cesarean scar pregnancies in our clinic. These were; Observational approach, Dilatation, and Curettage (D/C) procedure, D/C plus Systemic Methotrexate (MTX) Therapy, Systemic MTX therapy, Local MTX Therapy, and Combined Methotrexate Therapy. $50 \mathrm{mg} / \mathrm{m}^{2}$ MTX via intramuscular administration was used for systemic MTX therapy. An oocyte retrieval needle with $25 \mathrm{mg}$ MTX was used for the local MTX therapy. Details of the procedures are defined in the Supplementary Material 1.

\section{Statistical Analysis and Ethical Implications}

Basic demographic indicators and descriptive statistics were calculated with SPSS Statistics 23, (IBM Corporation, NY, USA) and Excel spreadsheet (Microsoft Windows Excel 2016, Redmond, WA, USA)]. Measurements are presented as individual values and means. Institutional ethics committee approval was obtained for the analysis of this retrospective data (2017-18/24).

\section{RESULTS}

Thirty-one CSP patients detected in our hospital records within six years. Demographic characteristics of the patients and the main aspects of the treatments are shown in Table 1. Six treatment modalities used in our clinic are explained in detail in Figure 1.

\section{FHA:(+) CSP patients}

Fetal heart activity was positive in 18 patients (58.06\%). Patient-13 was evaluated with the observational approach because of her request for the continuation of her pregnancy by undertaking all the risks.

We performed a D/C procedure to five patients ( $\mathrm{Pa}$ tient 3, 10, 17, 21 and 26). Patient 3, 10, 21 and 26 were treated after $\mathrm{D} / \mathrm{C}$ procedure. Patient 17 received an additional treatment of revision curettage on the second day after D/C with a rest placental fragment and abundant vaginal bleeding indication. CSP recurred in Patient 3 and 10 in their subsequent pregnancy despite the successful $\mathrm{D} / \mathrm{C}$ treatment. In total, three of the five patients who underwent the $\mathrm{D} / \mathrm{C}$ procedure were treated $(60 \%)$, but two were recurrent cesarean scar pregnancies again in their next pregnancy (40\%).

Five patients (Patient 12, 23, 25, 30 and 31) were treated with D/C plus systemic MTX therapy, and all of them were treated.

There were no patients treated with local MTX therapy in FHA:(+) CSP patients.

Patient 4 and Patient 24 received systemic MTX therapy. Patient 4 was treated while Patient 24 had an additional treatment due to the B-HCG levels which were drawing plateau. She received second systemic MTX therapy after one week later from the first systemic MTX treatment and was treated in 31 days.

Combined MTX treatment was used in 5 patients ( $\mathrm{Pa}$ tient 2, 6, 9, 20 and 22). All of them were treated. Patient 6 and 9 conceived after combined MTX treatment of cesarean scar pregnancies. 


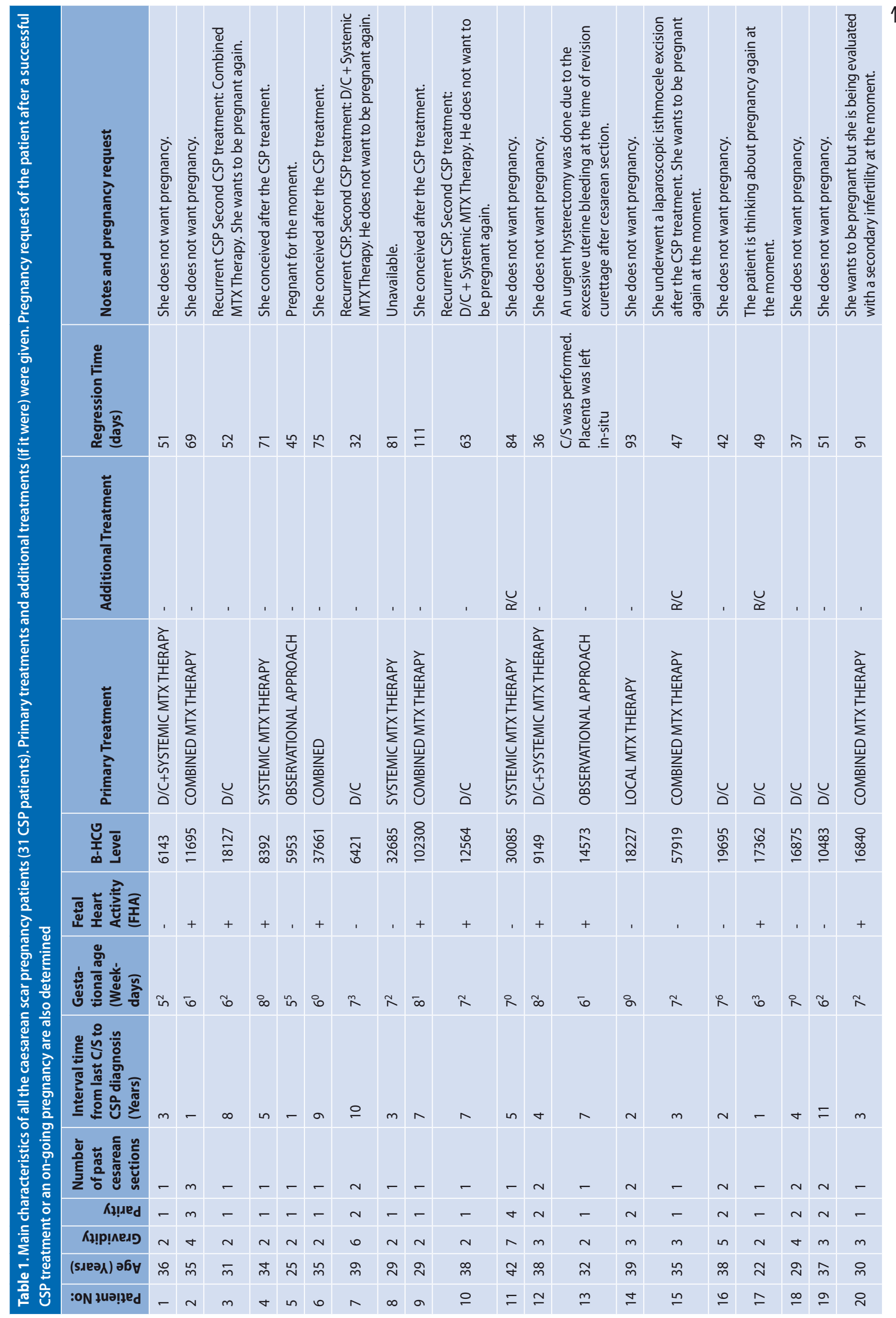




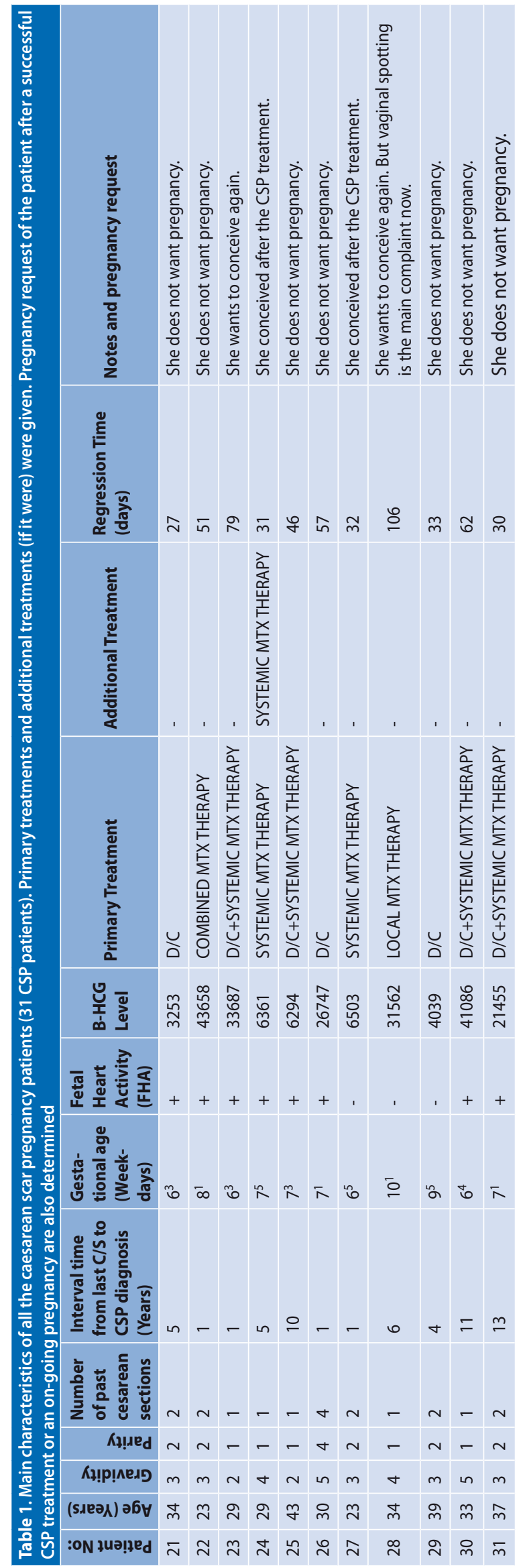

\section{FHA:(-) CSP patients}

There was only one patient (Patient 5) who were treated with the observational approach.

Five patients (Patient 7, 16, 18, 19 and 29) underwent a D/C procedure, and all of them were treated. Patient 7 was diagnosed with recurrent CSP after 100 days from the D/C procedure. Systemic MTX and D/C procedure were administrated, and she was treated in 21 days.

Only Patient 1 was treated with $D / C$ procedure plus systemic MTX therapy together in FHA:(-) CSP patients.

There were two patients (Patient 14 and 28) who received local MTX therapy in FHA:(-) CSP patients.

Systemic MTX therapy was administered to Patient 8 , 11 and 27 (Fig. 2). However, an urgent revision curettage was required in Patient 11 after 55 days from the CSP treatment due to the excessive vaginal bleeding. Patient 27 conceived 623 days after the CSP treatment.

Combined MTX therapy was performed to Patient 15. However, an additional revision curettage had to be performed 28 days after the CSP treatment due to the abundant vaginal bleeding. She was treated in 47 days. 74 days later this woman underwent a laparoscopic cesarean scar defect (isthmocele) excision with an indication of postmenstrual spotting and pelvic pain. Detailed timeline graphics of all the CSP patients are shown in detail in Supplementary Material 2.

\section{Patients conceived in clinical follow-up after the CSP treatment}

Nine women conceived in clinical follow-up after B-HCG levels were negative in their first CSP treatments (Fig. 2). Three women (Patient 3, 7 and 10) were diagnosed as CSP again. The remaining six patients (Patient 4, 5, 6, 9, 24 and 27) were conceived spontaneously on clinical follow-up (Fig. 3). Five patients had regular pregnancy follow-up and underwent cesarean section at 33rd gestational weeks in patient 4, 35th weeks in patient 6,34th weeks in patient 9,35 th weeks in patient 24 and 34th weeks in patient 27 respectively. Patient 5 was still pregnant at the time of writing this article. Perinatal and neonatal outcomes of the patients who conceived after the CSP treatments are shown in Table 2. Abnormal placental invasion or morbidly adherent placenta was not found in pregnancies of these patients. However, an incomplete rupture observed at the previous cesarean scar site during cesarean section in 3 patients (Patient 6, 9 and 27).

\section{Recurrent CSP patients}

After successful treatment of the CSPs, three patients (Patient 3, 7 and 10) were detected as recurrent CSP in their next pregnancy (Fig. 2). Patient 7 and Patient-10 treated with $\mathrm{D} / \mathrm{C}$ (As their gestational sac were adjacent to the cervical 


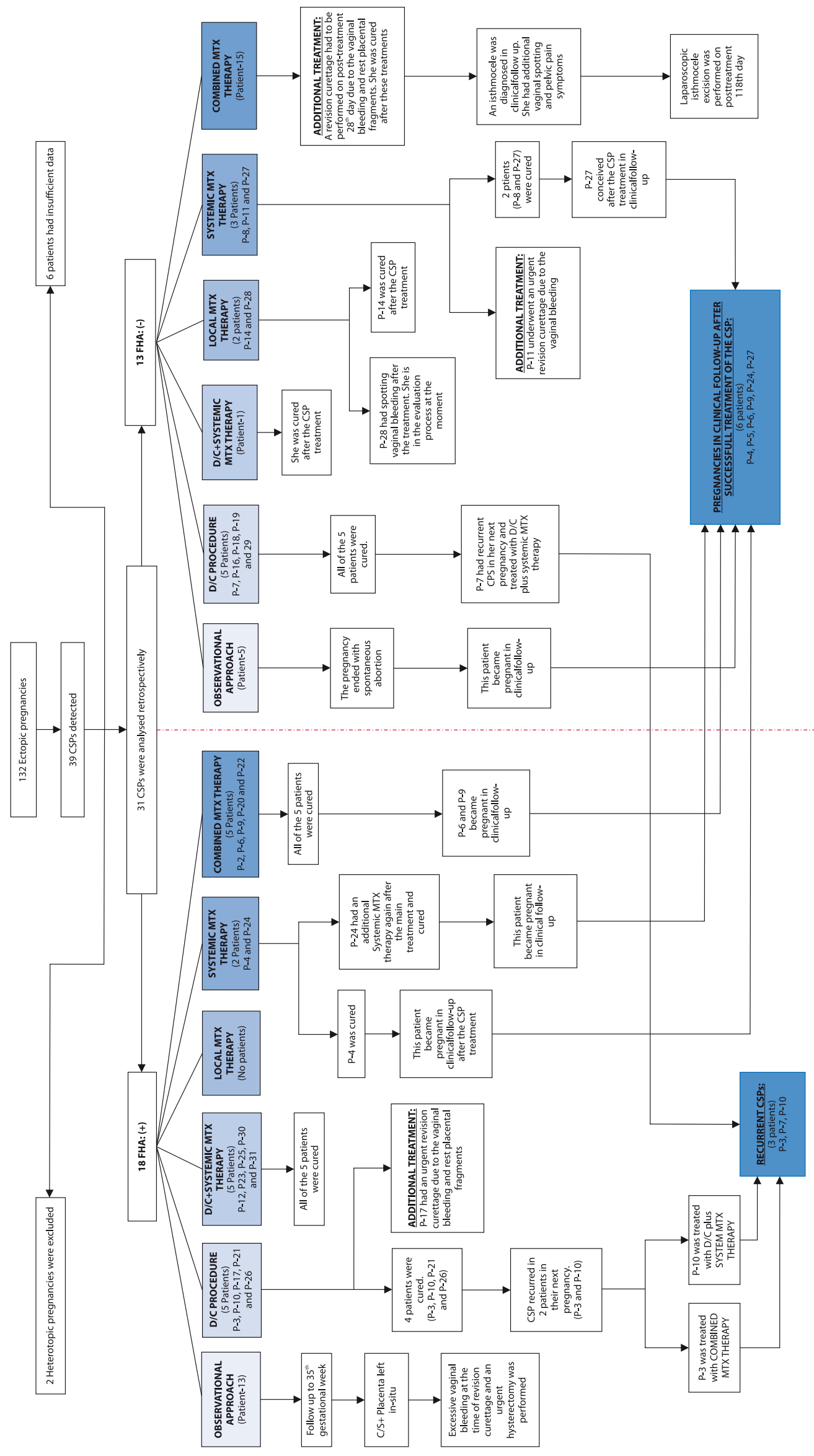

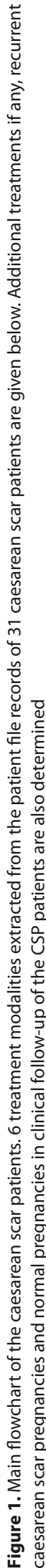




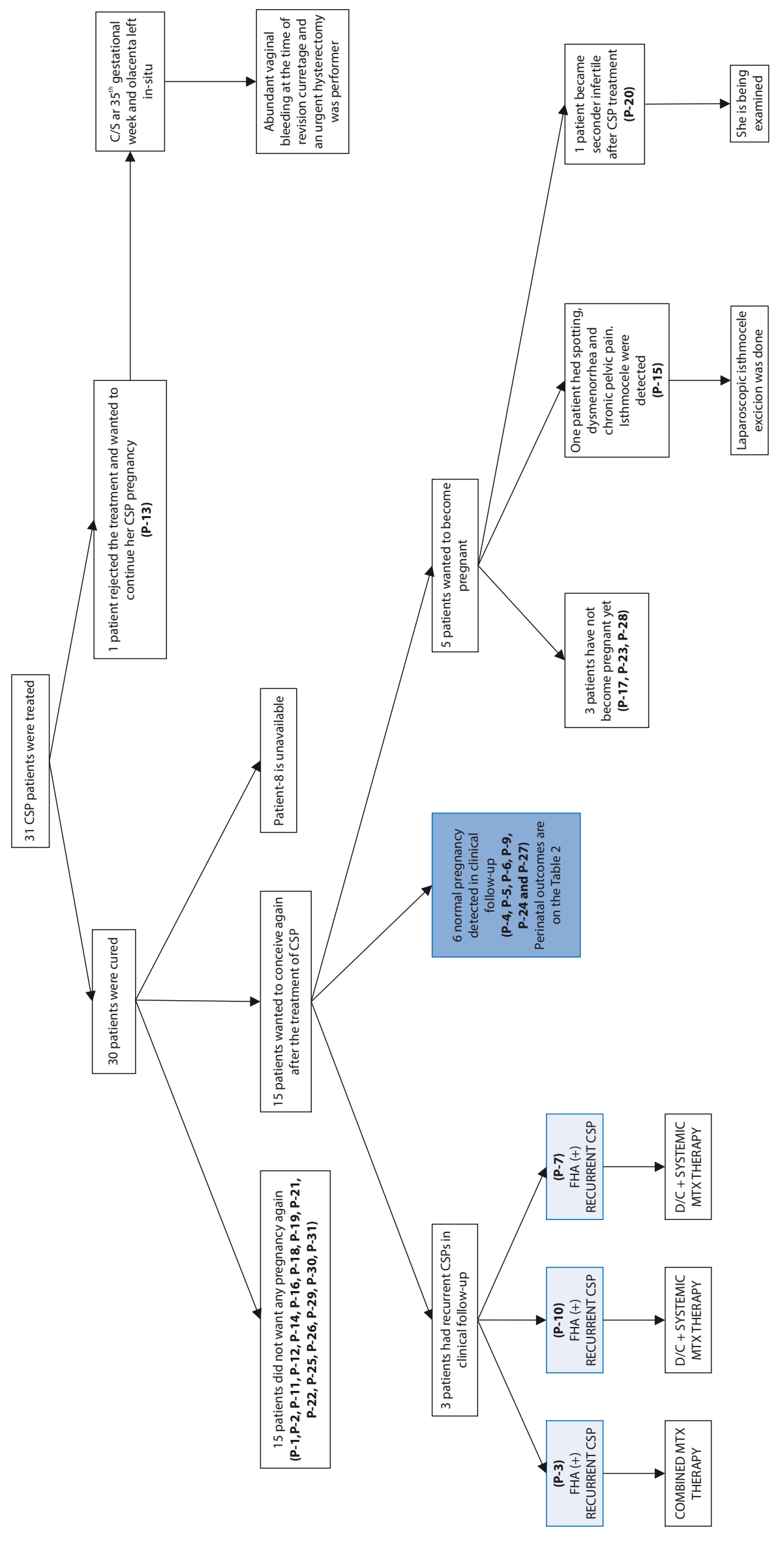

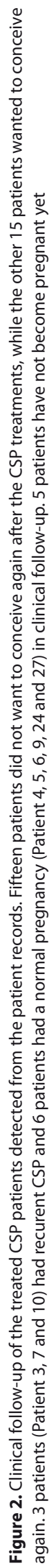



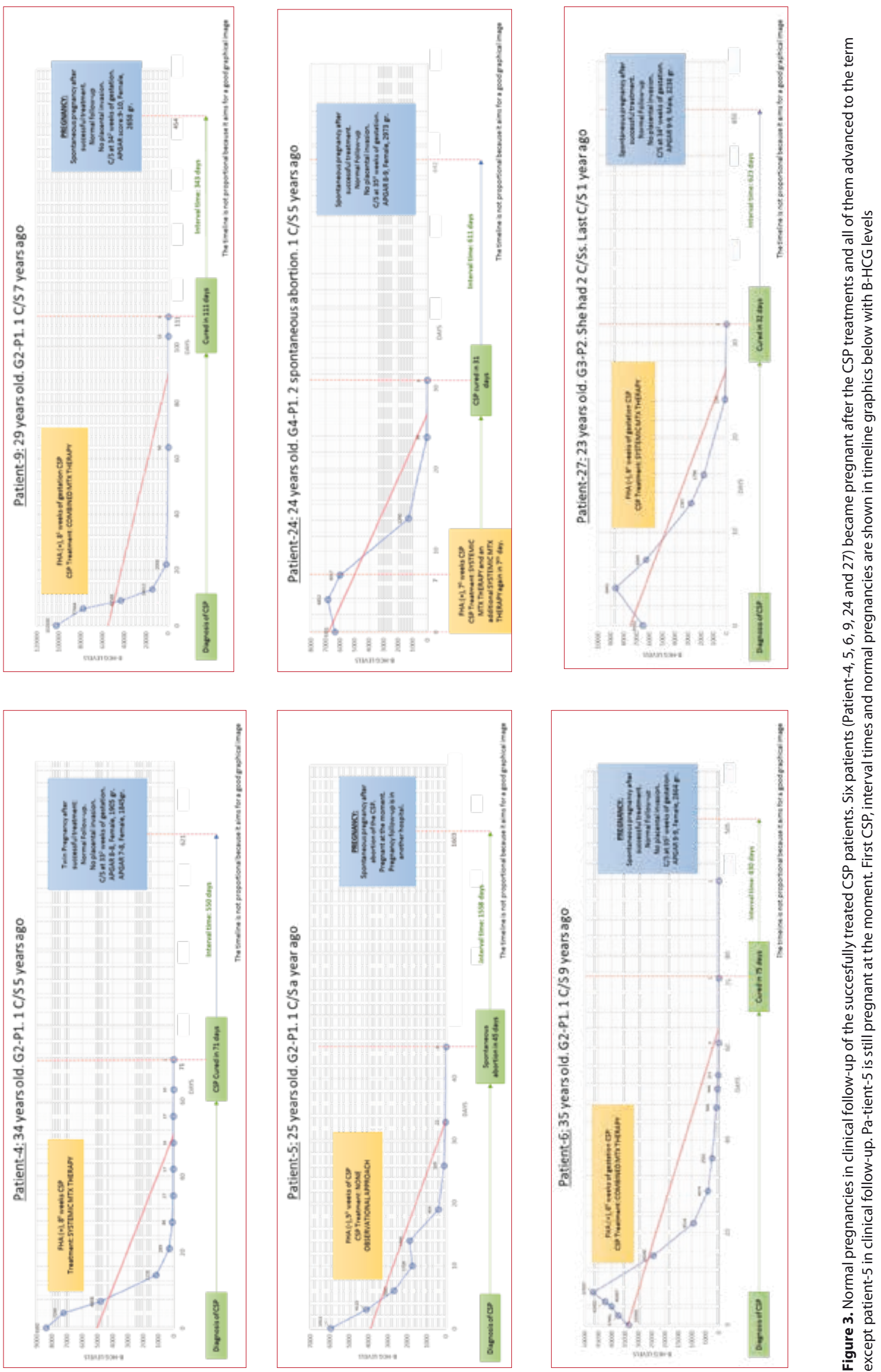
Table 2. Perinatal and pregnancy outcomes of caesarean scar pregnancy patients who were successfully treated and became pregnant again in clinical follow-up.

\begin{tabular}{|c|c|c|c|c|c|c|c|c|c|}
\hline \multirow{3}{*}{ Patient-4 } & \multirow{3}{*}{$\begin{array}{l}\text { Gestational } \\
\text { week } \\
33^{2} \text { weeks twin } \\
\text { pregnancy }\end{array}$} & \multirow{3}{*}{$\begin{array}{l}\text { Delivery } \\
\text { route } \\
\mathrm{C} / \mathrm{S}\end{array}$} & \multicolumn{2}{|c|}{ AGGAR scores } & \multicolumn{2}{|c|}{$\begin{array}{l}\text { Newborn } \\
\text { weight (gr) }\end{array}$} & \multicolumn{2}{|l|}{ Gender } & \multirow{3}{*}{$\begin{array}{l}\text { Notes } \\
\text { Twin pregnancy. No complication until birth. }\end{array}$} \\
\hline & & & 8 & 9 & \multirow{2}{*}{1905} & \multirow{2}{*}{1845} & \multirow{2}{*}{ Female } & \multirow{2}{*}{ Female } & \\
\hline & & & 7 & 8 & & & & & \\
\hline Patient-5 & $\begin{array}{l}\text { Pregnant at } \\
\text { the moment }\end{array}$ & - & - & - & - & & - & & $\begin{array}{l}\text { She is now in the } 21 \text { st gestational week and have } \\
\text { not any complication of pregnancy. }\end{array}$ \\
\hline Patient- 6 & $\begin{array}{l}35^{1} \text { weeks } \\
\text { pregnancy }\end{array}$ & $\mathrm{C} / \mathrm{S}$ & 9 & 9 & 2864 & & Female & & $\begin{array}{l}\text { Bilateral tubal ligation was performed at the } \\
\text { time of cesarean section. Incoplete rupture was } \\
\text { detected at the time of cesarean section. }\end{array}$ \\
\hline Patient-9 & $\begin{array}{l}34^{2} \text { weeks } \\
\text { pregnancy }\end{array}$ & $\mathrm{C} / \mathrm{S}$ & 9 & 10 & 2658 & & Female & & $\begin{array}{l}\text { Oligohydramnios was observed at } 30 \text { th } \\
\text { gestational week and she delivered via } \mathrm{C} / \mathrm{S} \text {. } \\
\text { Incomplete rupture were detected at the time of } \\
\text { cesarean section. }\end{array}$ \\
\hline Patient-24 & $\begin{array}{l}35^{4} \text { weeks } \\
\text { pregnancy }\end{array}$ & $\mathrm{C} / \mathrm{S}$ & 8 & 9 & 2973 & & Female & & $\begin{array}{l}\text { Preterm labor was complicated the pregnancy } \\
\text { and } C / S \text { was performed. }\end{array}$ \\
\hline Patient-27 & $\begin{array}{l}34^{2} \text { weeks } \\
\text { pregnancy }\end{array}$ & $\mathrm{C} / \mathrm{S}$ & 9 & 9 & 3238 & & Male & & $\begin{array}{l}\text { Incomplete rupture was detected at the time of } \\
\text { cesarean section. Postpartum depression was } \\
\text { diagnosed. She was consulted with psychiatry } \\
\text { clinic. }\end{array}$ \\
\hline
\end{tabular}

canal) plus systemic MTX therapy and Patient 3 with combined MTX therapy. Detailed timeline graphics of recurrent CSP cases are shown in Figure 4.

\section{DISCUSSION}

With the increase of the cesarean rates, two main clinical conditions which are early placenta accreta and CSP have threatened the subsequent pregnancy of the women in recent years. Both of these complications may risk women's life [13]. While placental invasion abnormalities have long been a primary concern of obstetrics, the definition of CSP is a new clinical entity. As cesarean rates increase, more patients are diagnosed with CSP every year [5].

There are two fundamental problems in managing CSPs. The first problem is the diagnose, which is really difficult for CSPs especially for clinicians working in the primary care centers [14]. The second and the main problem is the treatment. Experiences about diagnosis are increasing day by day. However, the same situation cannot be applied to the treatment since there are no established guidelines in CSP treatment. In a study, combined local and systemic MTX treatment was found to be effective in 19 out of 26 cases [13]. In our data, five FHA:(+) CSP patients treated with combined treatment and all of them were treated. Two patients were pregnant afterward and delivered healthy babies via cesarean section.

The observational approach in CSP may have problematic consequences. In an article with 60 cases, high-rate hysterectomy had to be performed in cases which an observational approach was applied [15]. In our study, two patients requested the continuation of CSP pregnancy. We had to perform a hysterectomy to Patient 13 . Patient
5 who had an FHA:(-) CSP, was spontaneously aborted in clinical follow-up. Similarly, in a recently published review, it was stated that CSPs with negative fetal heart activity might terminate spontaneously in expectant management [16].

What is the most significant complication if the patient is diagnosed with CSP and wants to continue her pregnancy? The answer is inevitably morbidly adherent placenta. If an observational approach is applied, almost all of these women develop MAP. In a trial, ten CSP cases evaluated with the observational approach and MAP observed in all of them [9]. However, all of these patients undergoing the observational approach were FHA:(+) CSP patients. The observational approach was noted only in two women in our study. A placenta accreta with early diagnosis and a CSP case cannot be distinguished from each other histopathologically [17]. Both of these clinical entities will inevitably advance to MAP. Therefore, if an FHA:(+), CSP woman is to be followed up with an observational approach then she should be informed in detail about the catastrophic consequences of the treatment including hysterectomy.

The D/C procedure has always been up to date since the CSP definition was first introduced in the late seventies [4]. It is safer and cost-effective when done in guidance with USG $[18,19]$. However, the most fundamental problem of this procedure is the distance between CSP sac and the cervical canal. Because the longer the range of CSP-cervical canal is, the harder it is to reach CSP with the curette. Therefore, the use of the $\mathrm{D} / \mathrm{C}$ procedure alone in the treatment of CSP significantly reduces success rates [20]. In a recent review, it has stated that the $D / C$ procedure could be successful only with the addition of other treatments such as uterine 

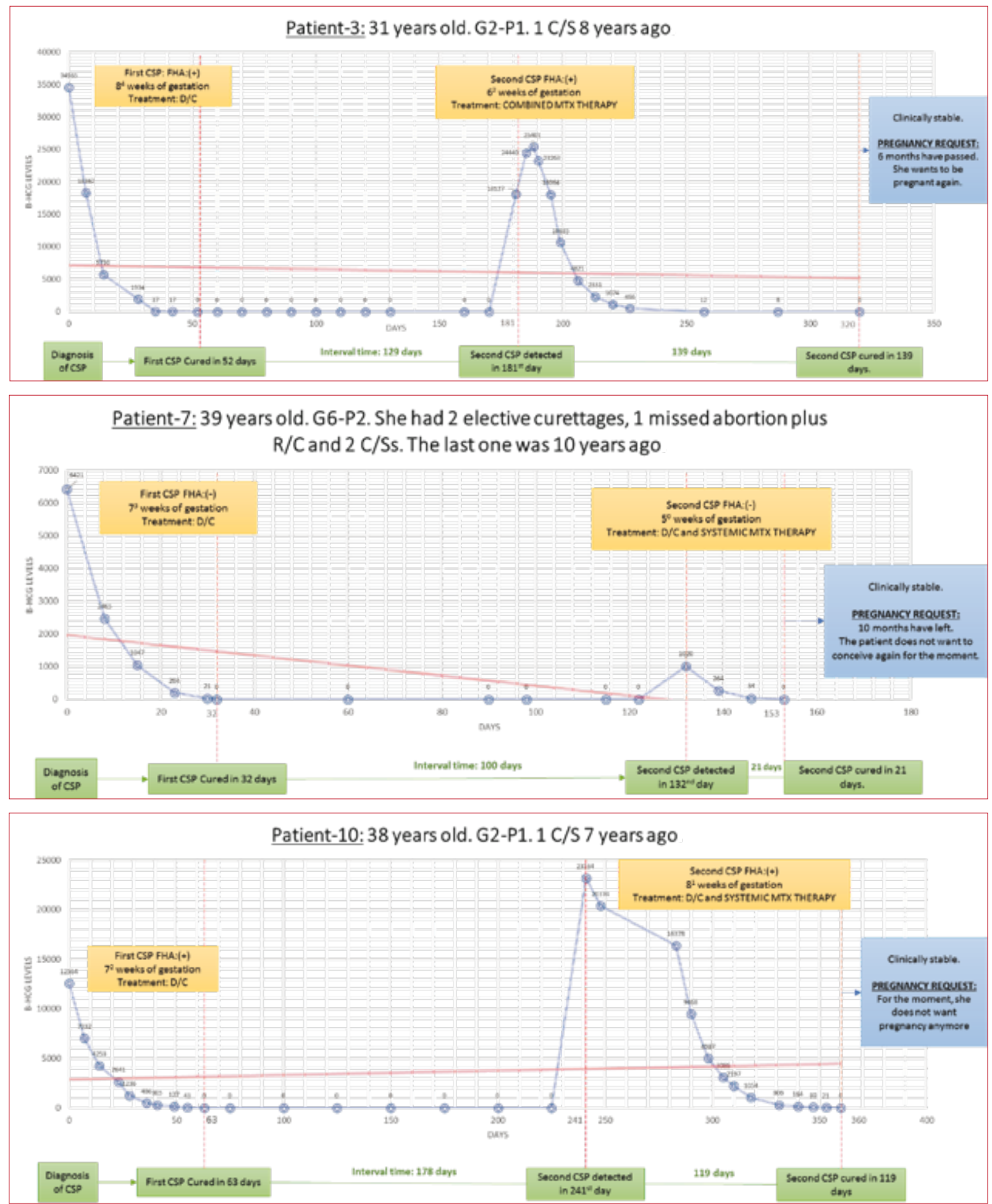

Figure 4. Recurrent CSP patients. There were 3 recurrent CSP cases (Patient-3, 7 and 10) detected from the patient files in clinical follow-up of the treated CSP patients. All of these three patients were treated with D/C procedure in their first caesarean scar pregnancies. After diagnosis of recurrent CSP, patient-3 were treated with combined MTX therapy. While patient 7 and 10 were treated with D/C plus systemic MTX therapy

artery embolization or MTX therapy [21]. We have observed that the most significant handicap of the $D / C$ procedure is recurrent CSP. Three recurrent CSP cases in our series were treated by only D/C procedure in their first CSP. However, CSP patients who treated with D/C plus systemic MTX therapy were all treated, and none of them recurred. It can be hy- 
pothesized that while $\mathrm{D} / \mathrm{C}$ procedure alone is inadequate in the treatment of CSP, D/C plus systemic MTX therapy may be useful. Since the recurrent CSP is ubiquitous after the $\mathrm{D} / \mathrm{C}$ procedure, a recent trial has shown that the operative hysteroscopy is useful in such cases [22].

Non-surgical treatments might also be of interest in the treatment of CSP. Uterine artery embolization may be useful in CSPs presenting with acute bleeding [23]. The most popular non-surgical treatment modality is a chemotherapeutic agent administration of a local injection into the CSP sac [24]. Two women who had FHA:(-) CSP, received local MTX treatment in our cohort. Complete cure was achieved in Patient 14 but Patient 28 has still complaints about vaginal spotting, and she is in the clinical evaluation process at the moment. Clinicians usually want to try the local treatment in locally accessible patients or in cases where CSP does not spread volumetrically. We think that some main anatomical measurements such as the volume of CSP, the distances between CSP-bladder, CSP-cervical canal, CSP-fundus uteri, and CSP-external cervical os should be evaluated to predict which CSP patient will be sufficient for the local treatment. Another point is that it is unknown why systemic MTX therapy has not been used with local MTX therapy and also it is unknown which treatment (local, systemic or combined) should be given to which patient.

Which CSPs can be advanced to the term is controversial. In a recent review, the concept of endogenous and exogenous growth has been put forward [25]. A CSP which has a potential for endogenous growth, can migrate towards the fundus and then reach the term. However, the CSP which has a potential for exogenous growth is expanding directly into the bladder and can lead to catastrophic outcomes. Although we did not perform any in our series, laparoscopic management of CSP in a previous cesarean section scar with exogenous growth can also be considered as an effective treatment method [26].

Noninvasive treatments can be a factor in conceiving again in CSPs. Conducting pharmacological therapies rather than a destructive treatment as in D/C procedure may facilitate normal pregnancy in the clinical follow-up of the treated CSP patients. The absence of placental invasion anomalies in six pregnancies may be seen as a limitation of this study because at least one placental invasion anomaly would have to be observed according to similar retrospective studies [10].

In conclusion, the treatment stages of CSP, which clinicians have encountered more and more in recent years, have not been standardized yet. Successful treatment of CSPs with different treatment modalities may be possible. The trials in this area consist of numerous retrospective analyzes as it is in our study and more randomized trials are needed to be done.

\section{Conflict of interests}

All authors have no conflicts of interests to declare.

\section{REFERENCES}

1. Betrán AP, Ye J, Moller AB, et al. The Increasing Trend in Caesarean Section Rates: Global, Regional and National Estimates: 1990-2014. PLoS One. 2016; 11(2): e0148343, doi: 10.1371/journal.pone.0148343, indexed in Pubmed: 26849801

2. Turkey Ministry of Health, Health Statistics Yearbook of 2015. http:// www.saglikistatistikleri.gov.tr/dosyalar/SIY_2015.pdf.

3. World Health Organization. 2016. "WORLD HEALTH STATISTICS- MONITORING HEALTH FOR THE SDGs." World Health Organization: 1.121.

4. Timor-Tritsch IE, Monteagudo A, Bennett TA, et al. The diagnosis, treatment, and follow-up of cesarean scar pregnancy. Am J Obstet Gynecol. 2012; 207(1): 44.e1-44.13, doi: 10.1016/j.ajog.2012.04.018, indexed in Pubmed: 22607667.

5. Shi M, Zhang $\mathrm{H}$, Qi SS, et al. Identifying risk factors for cesarean scar pregnancy: a retrospective study of 79 cases. Ginekol Pol. 2018; 89(4): 195-199, doi: 10.5603/GP.a2018.0033, indexed in Pubmed: 29781074.

6. Larsen JV, Solomon MH. Pregnancy in a uterine scar sacculus--an unusual cause of postabortal haemorrhage. A case report. S Afr Med J. 1978; 53(4): 142-143, indexed in Pubmed: 653492.

7. Jelsema RD, Zuidema L. First-trimester diagnosed cervico-isthmic pregnancy resulting in term delivery. Obstet Gynecol. 1992; 80(3 Pt 2): 517-519, indexed in Pubmed: 1495727.

8. Matyszkiewicz A, Jach R, Nocuń A, et al. [Cesarean scar pregnancy]. Ginekol Pol. 2015; 86(10): 791-798, indexed in Pubmed: 26677591.

9. Clark SL, Koonings PP, Phelan JP. Placenta previa/accreta and prior cesarean section. Obstet Gynecol. 1985; 66(1): 89-92, indexed in Pubmed: 4011075.

10. Rotas M, Haberman S, Levgur M. Cesarean Scar Ectopic Pregnancies. Obstetrics \& Gynecology. 2006; 107(6): 1373-1381, doi: 10.1097/01. aog.0000218690.24494.ce.

11. Jurkovic D, Hillaby K, Woelfer B, et al. First-trimester diagnosis and management of pregnancies implanted into the lower uterine segment Cesarean section scar. Ultrasound Obstet Gynecol. 2003; 21(3): 220-227, doi: 10.1002/uog.56, indexed in Pubmed: 12666214.

12. Comstock CH, Timor-Tritsch IE, Monteagudo A, et al. Cesarean scar pregnancy is a precursor of morbidly adherent placenta. Ultrasound Obstet Gynecol. 2014; 44(3):346-353, doi: 10.1002/uog.13426, indexed in Pubmed: 24890256.

13. Timor-Tritsch IE, Monteagudo A. Unforeseen consequences of the increasing rate of cesarean deliveries: early placenta accreta and cesarean scar pregnancy. A review. Am J Obstet Gynecol. 2012; 207(1): 14-29, doi: 10.1016/j.ajog.2012.03.007, indexed in Pubmed: 22516620.

14. Ash A, Smith A, Maxwell D. Caesarean scar pregnancy. BJOG. 2007; 114(3): 253-263, doi: 10.1111/j.1471-0528.2006.01237.x, indexed in Pubmed: 17313383

15. Timor-Tritsch IE, Khatib N, Monteagudo A, et al. Cesarean scar pregnancies: experience of 60 cases. J Ultrasound Med. 2015; 34(4): 601-610, doi: 10.7863/ultra.34.4.601, indexed in Pubmed: 25792575.

16. Calì G, Timor-Trisch IE, Palacios-Jaraquemada J, et al. Outcome of Cesarean Scar Pregnancy: A Systematic Review and Meta-Analysis. Int J Gynaecol Obstet. 2018; 140(3): 319-325.

17. Sinha P, Mishra M. Caesarean scar pregnancy: a precursor of placenta percreta/accreta. J Obstet Gynaecol. 2012; 32(7): 621-623, doi: 10.3109 101443615.2012.698665, indexed in Pubmed: 22943704.

18. Liu S, Sun J, Cai B, et al. Management of Cesarean Scar Pregnancy Using Ultrasound-Guided Dilation and Curettage. J Minim Invasive Gynecol. 2016;23(5): 707-711, doi: 10.1016/j.jmig.2016.01.012, indexed in Pubmed: 26803916.

19. Polat I, Ekiz A, Acar DK, et al. Suction curettage as first line treatment in cases with cesarean scar pregnancy: feasibility and effectiveness in early pregnancy. J Matern Fetal Neonatal Med. 2016; 29(7): 1066-1071, doi: 10.3109/14767058.2015.1034100, indexed in Pubmed: 25897638.

20. Birch Petersen K, Hoffmann E, Rifbjerg Larsen C, et al. Cesarean scar pregnancy: a systematic review of treatment studies. Fertil Steril. 2016; 105(4): 958-967, doi: 10.1016/j.fertnstert.2015.12.130, indexed in Pubmed: 26794422.

21. Maheux-Lacroix S, Li F, Bujold E, et al. Cesarean Scar Pregnancies: A Systematic Review of Treatment Options. J Minim Invasive Gynecol. 2017; 24(6): 915-925, doi: 10.1016/j.jmig.2017.05.019, indexed in Pubmed: 28599886.

22. Qian ZD, Weng Y, DuYJ, et al. Management of persistent caesarean scar pregnancy after curettage treatment failure. BMC Pregnancy Childbirth. 2017; 17(1): 208, doi: 10.1186/s12884-017-1395-4, indexed in Pubmed: 28666477.

23. Wozniak S, Pyra K, Kłudka-Sternik M, et al. Uterine artery embolization using gelatin sponge particles performed due to massive vaginal bleed- 
ing caused by ectopic pregnancy within a cesarean scar: a case study. Ginekol Pol. 2013; 84(11): 966-969, indexed in Pubmed: 24455855.

24. Monteagudo A, Minior VK, Stephenson C, et al. Non-surgical management of live ectopic pregnancy with ultrasound-guided local injection: a case series. Ultrasound Obstet Gynecol. 2005; 25(3): 282-288, doi: 10.1002/uog.1822, indexed in Pubmed: 15736204.
25. Gonzalez N, Tulandi T. Cesarean Scar Pregnancy: A Systematic Review. J Minim Invasive Gynecol. 2017; 24(5): 731-738, doi: 10.1016/j. jmig.2017.02.020, indexed in Pubmed: 28268103.

26. Spychała P, Nowakowski B. [Laparoscopic management of an ectopic pregnancy in a previous caesarean section scar]. Ginekol Pol. 2012; 83(8): 622-625, indexed in Pubmed: 23342888.
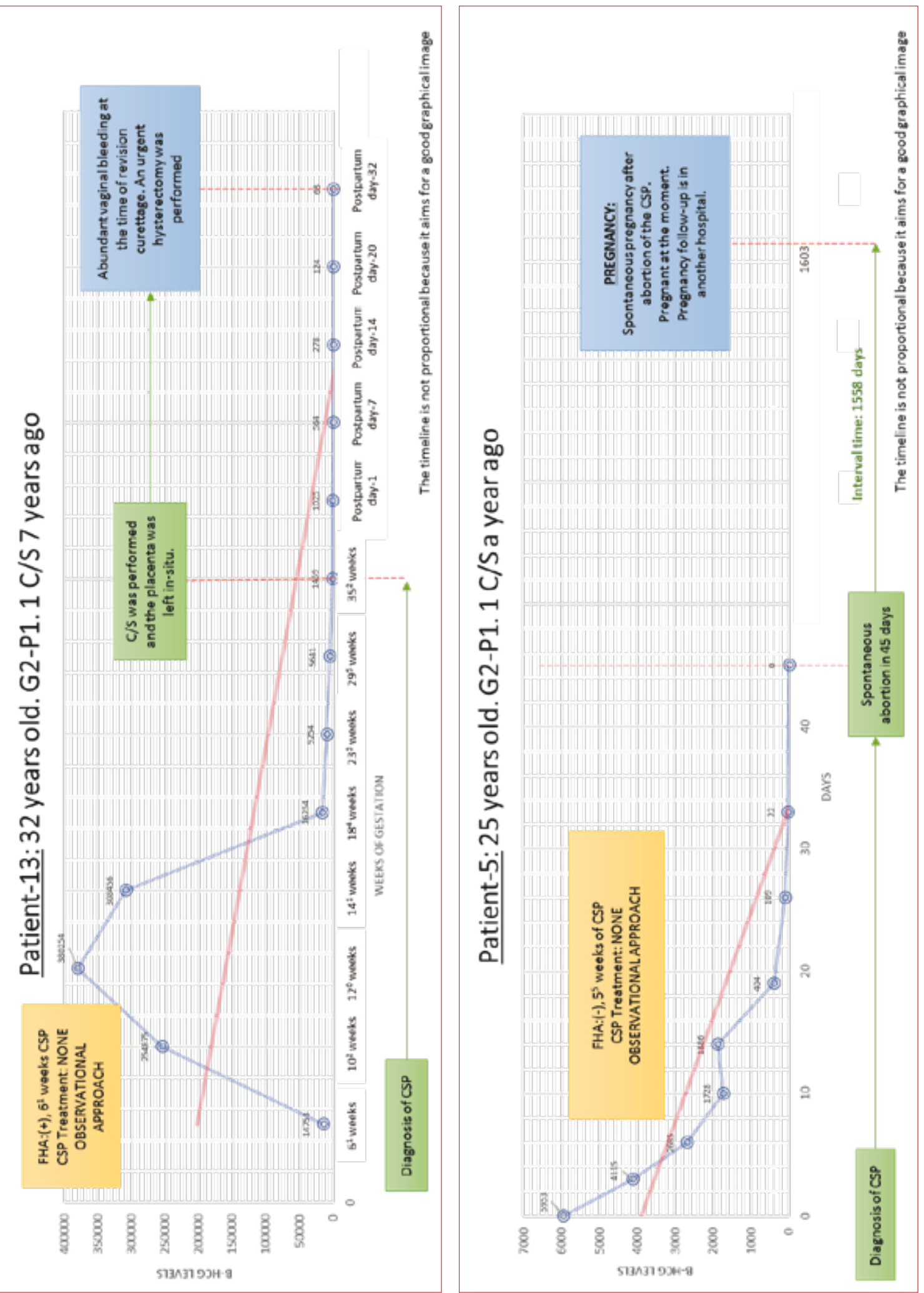

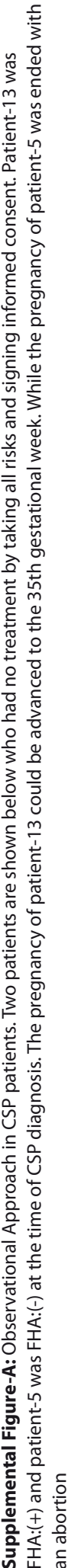



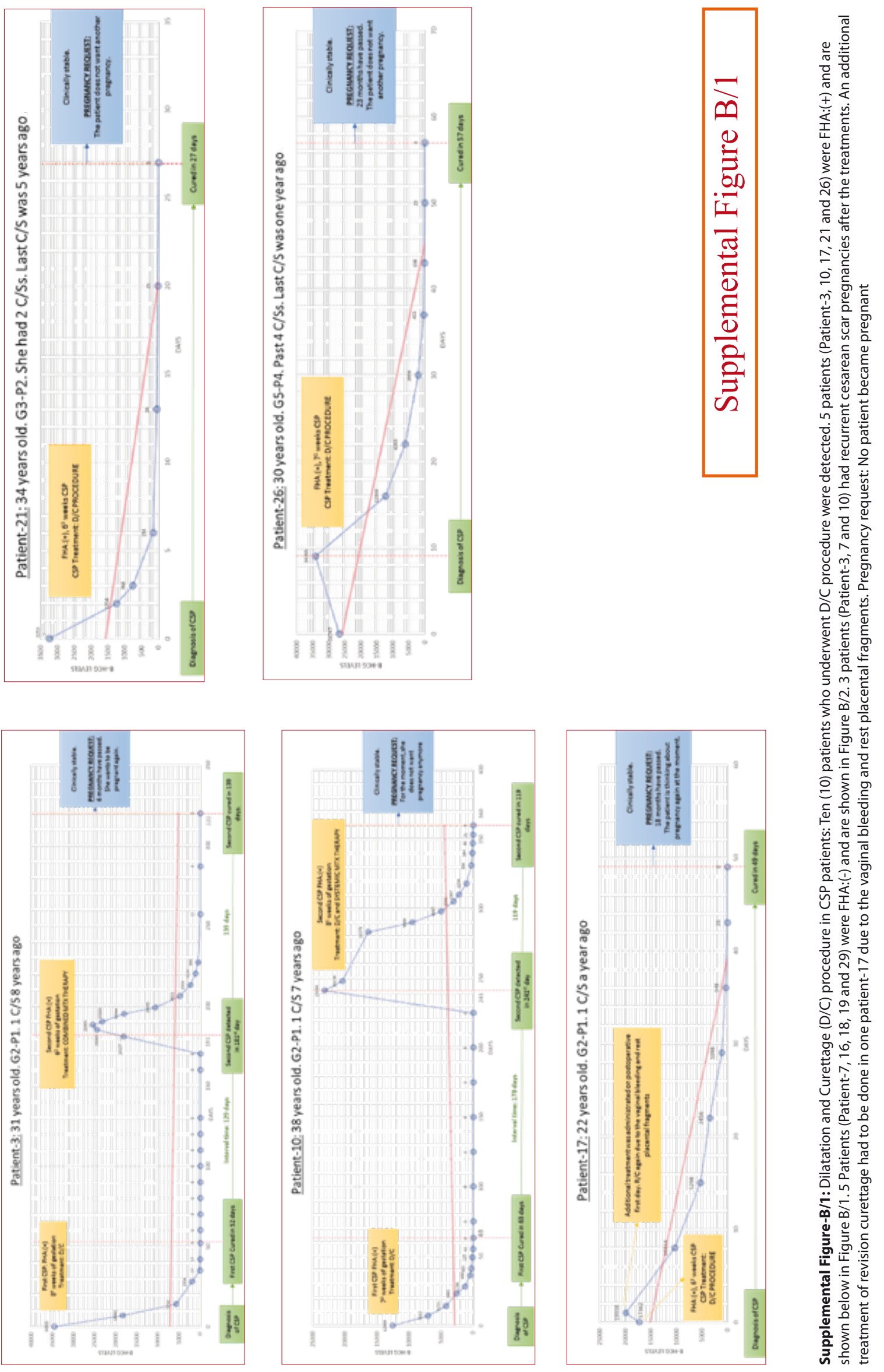

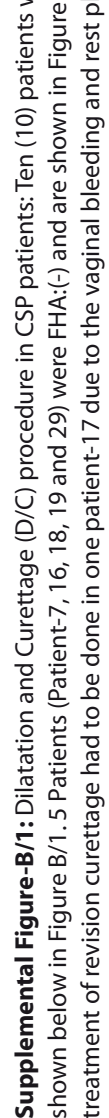



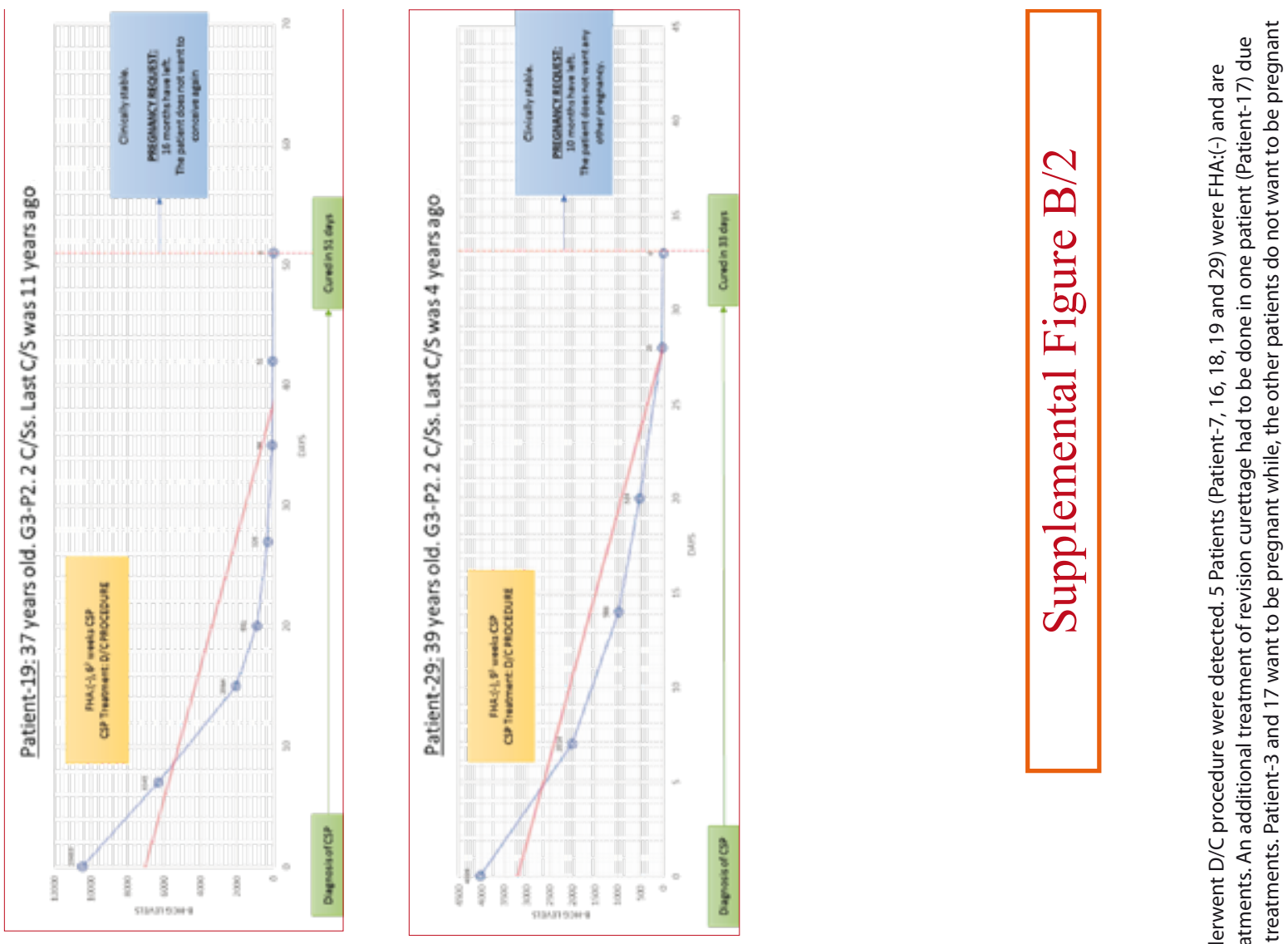

要焉

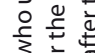
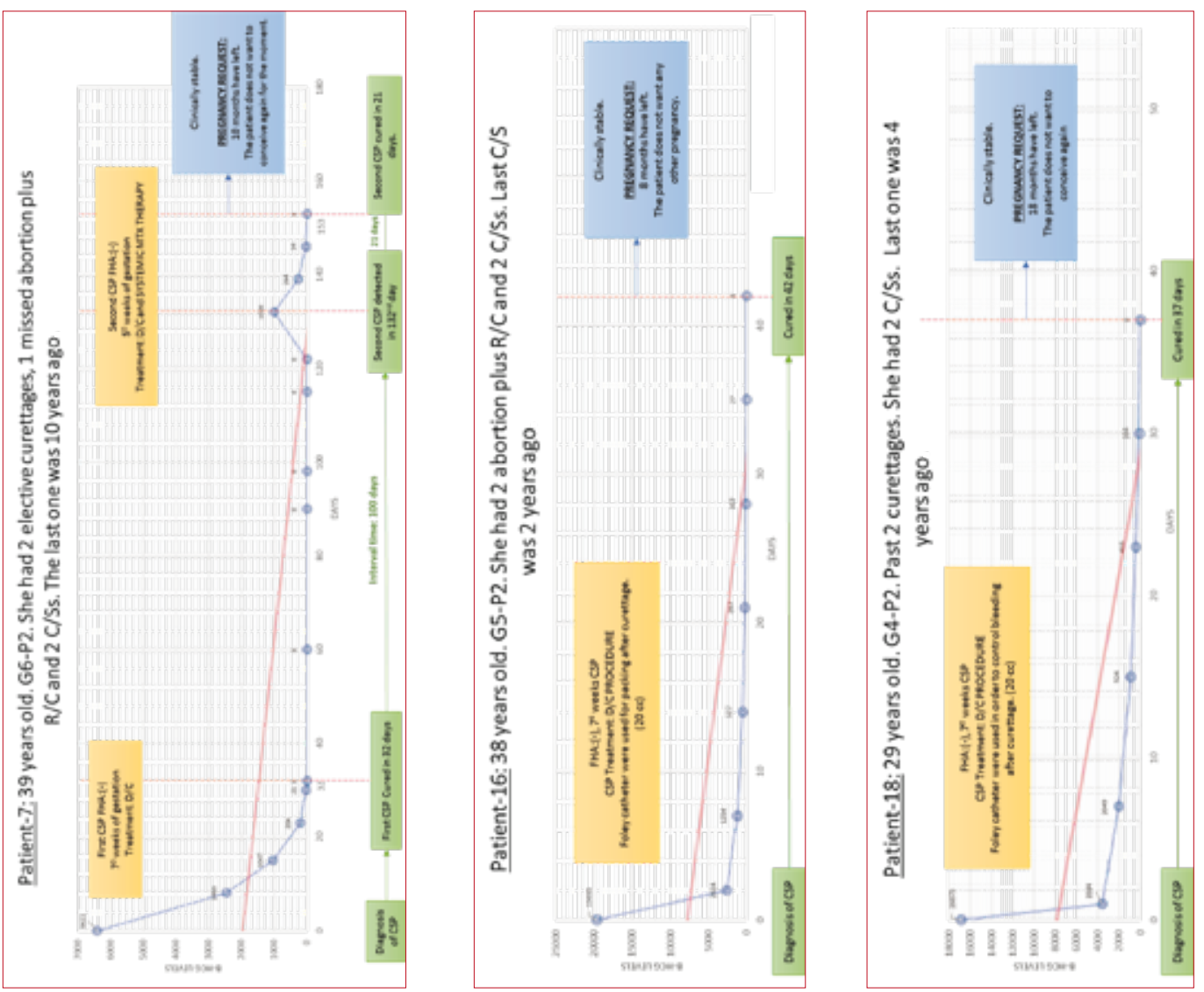

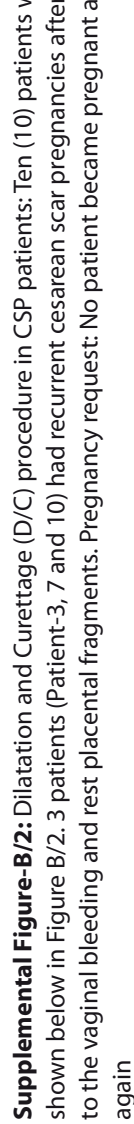



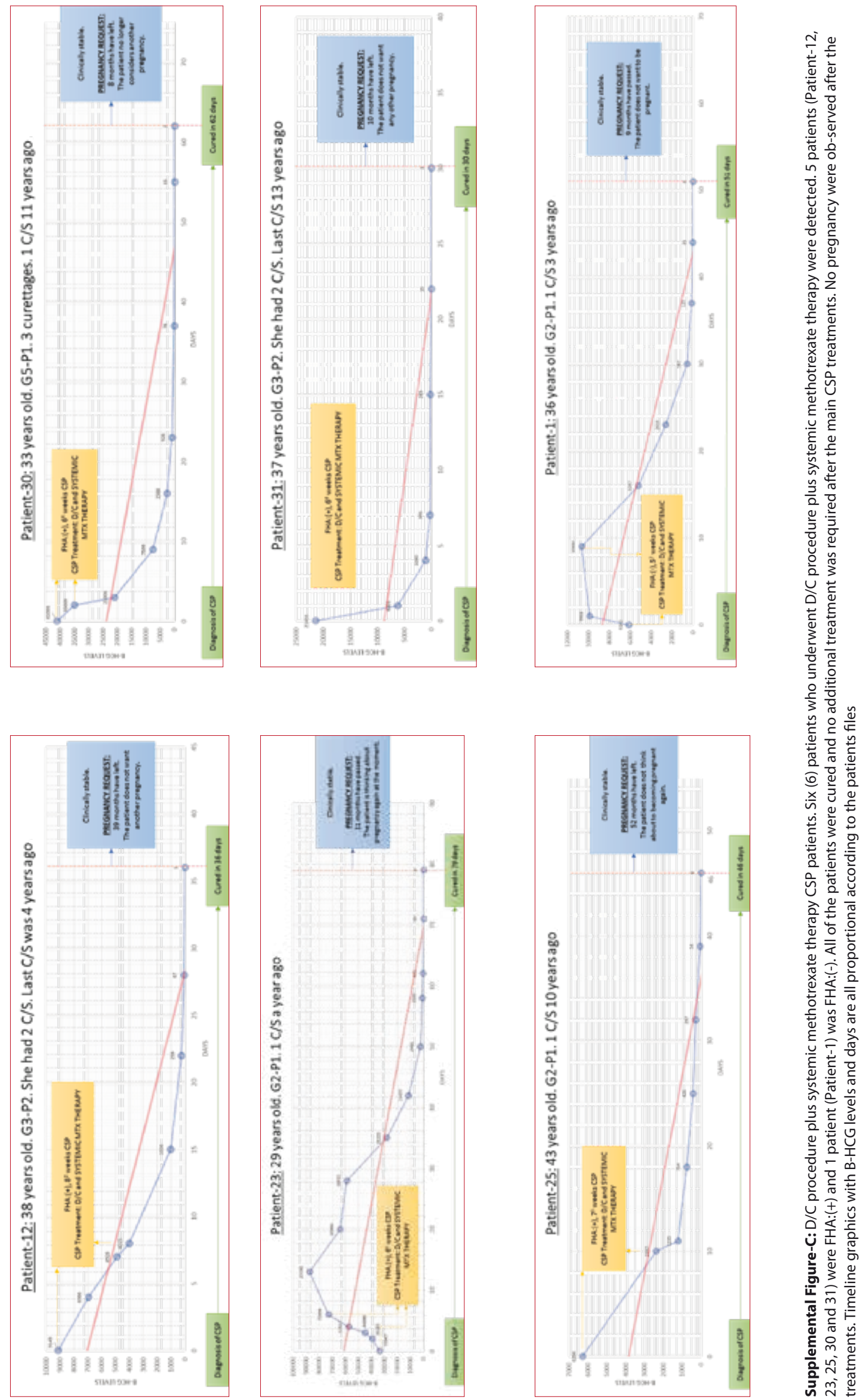

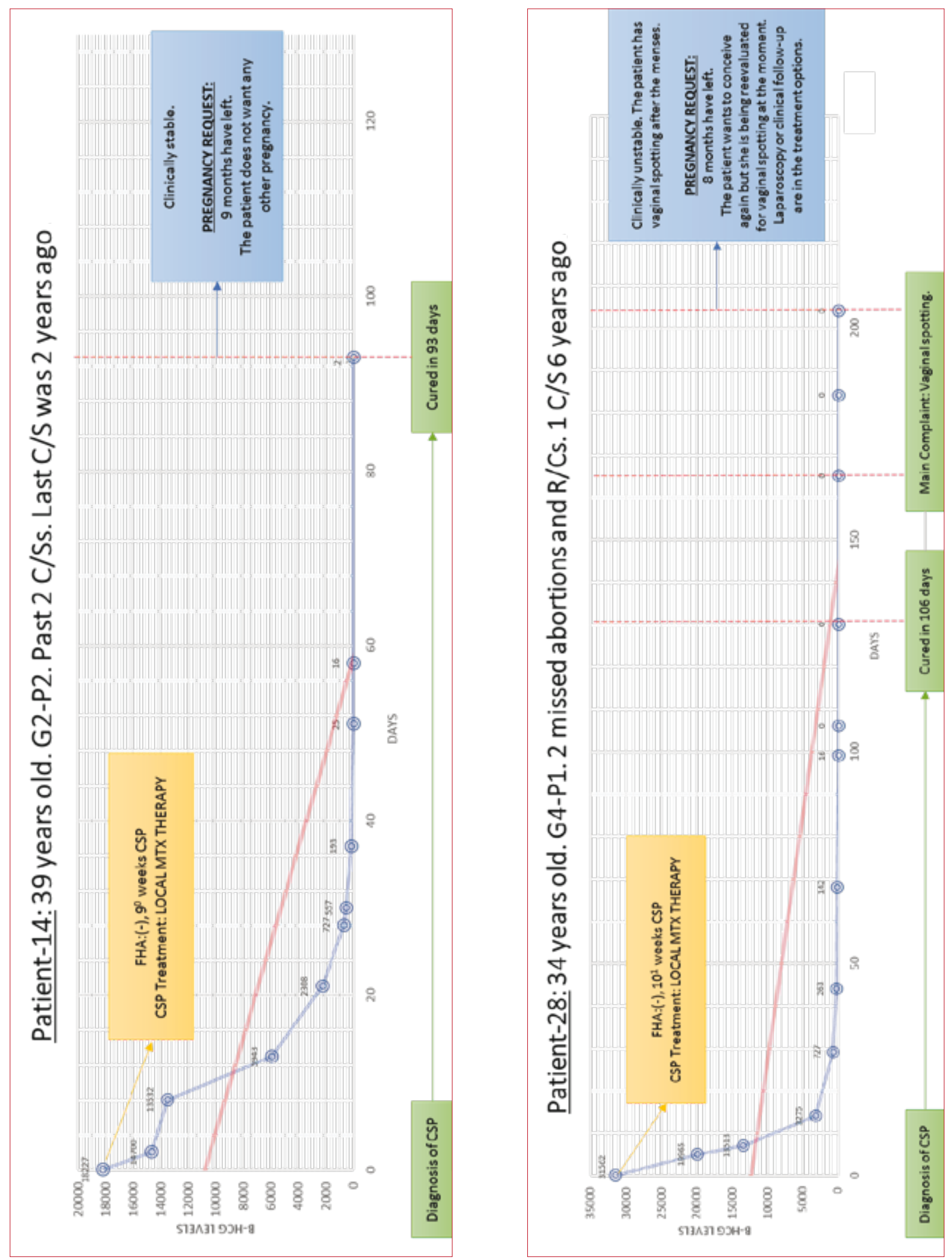

Supplemental Figure-D: Local MTX therapy administrated CSP patients. Scanning the patient records, there were no FHA:(+) CSP patients who were treated by local methotrexate therapy. Patient 14 and 28 were FHA:(-) CSP patients who were treated with local MTX. No pregnancy occured after the treatments in clinical follow-up. Patient 28 wants to conceive for the moment but she is being re-evaluated for the vaginal spotting 

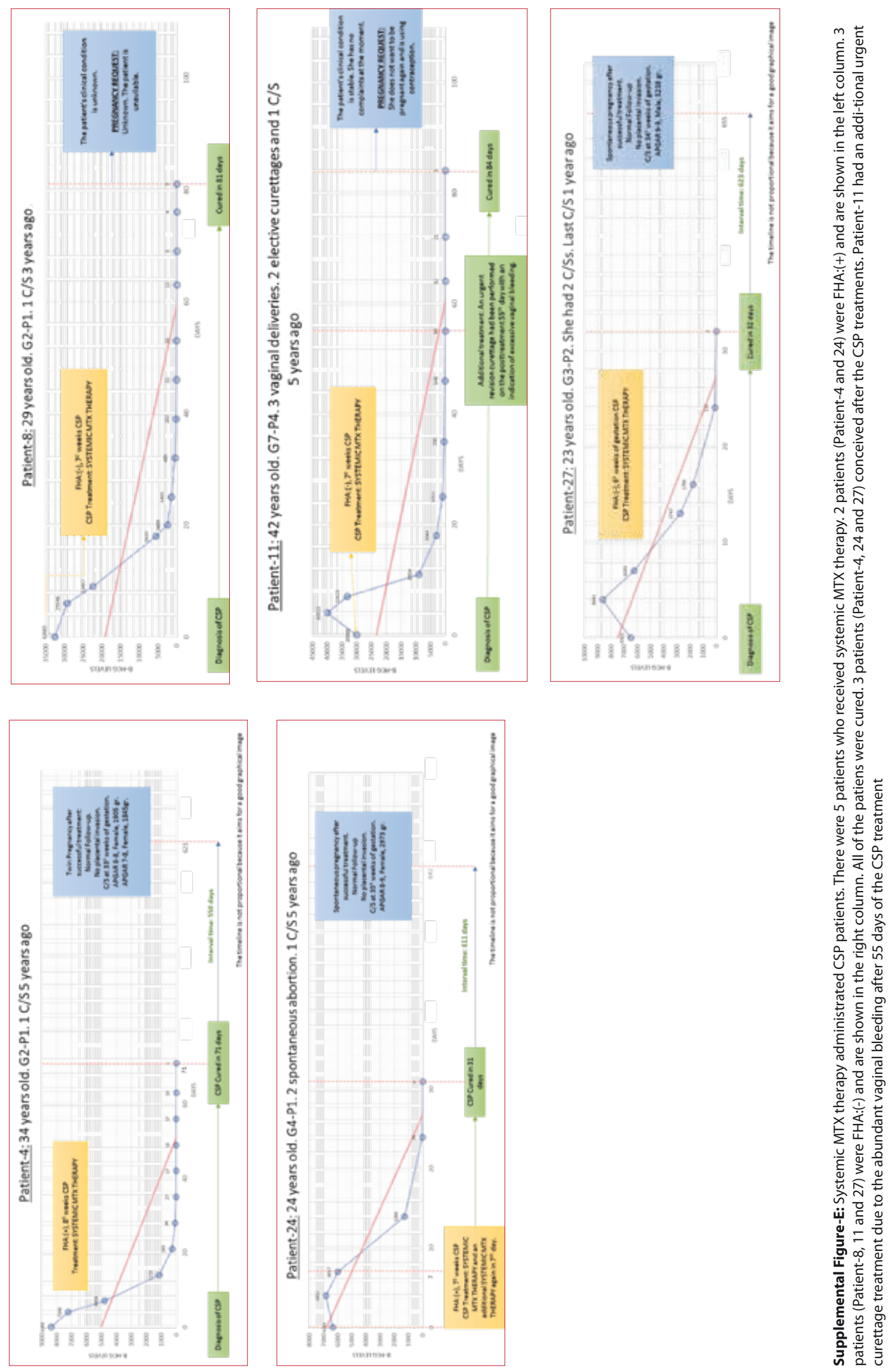

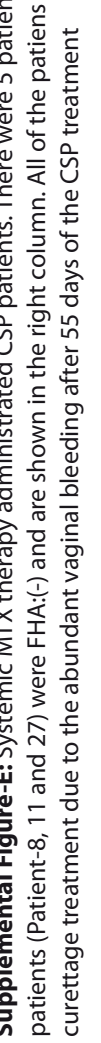



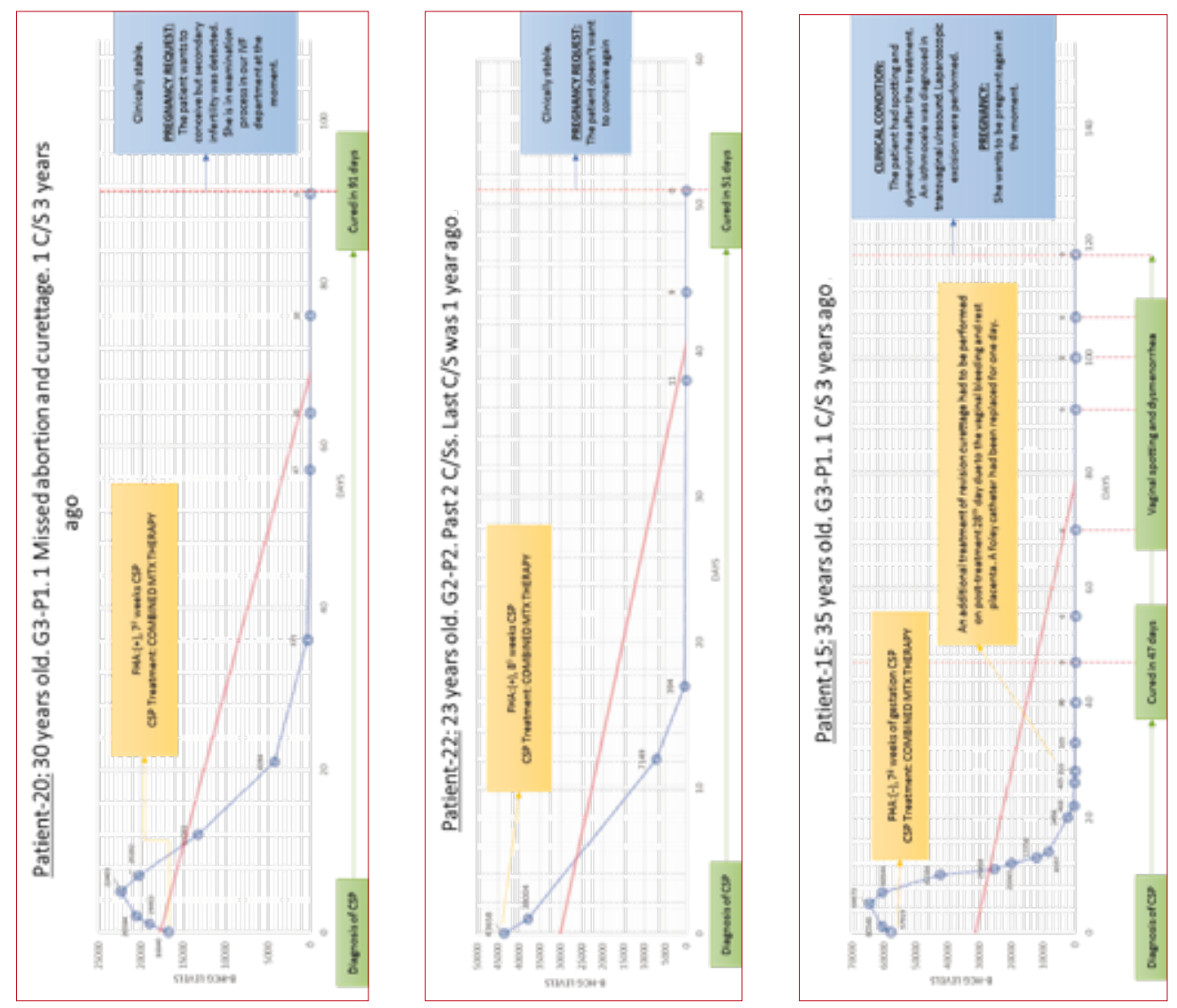

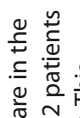

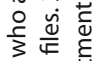

王菜要

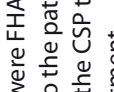

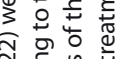

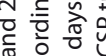

ก.

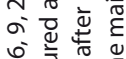

is

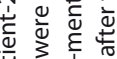

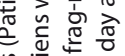

产语

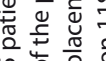

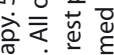

离部寄

×등

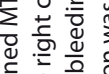

接

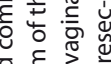

总

要

要

3
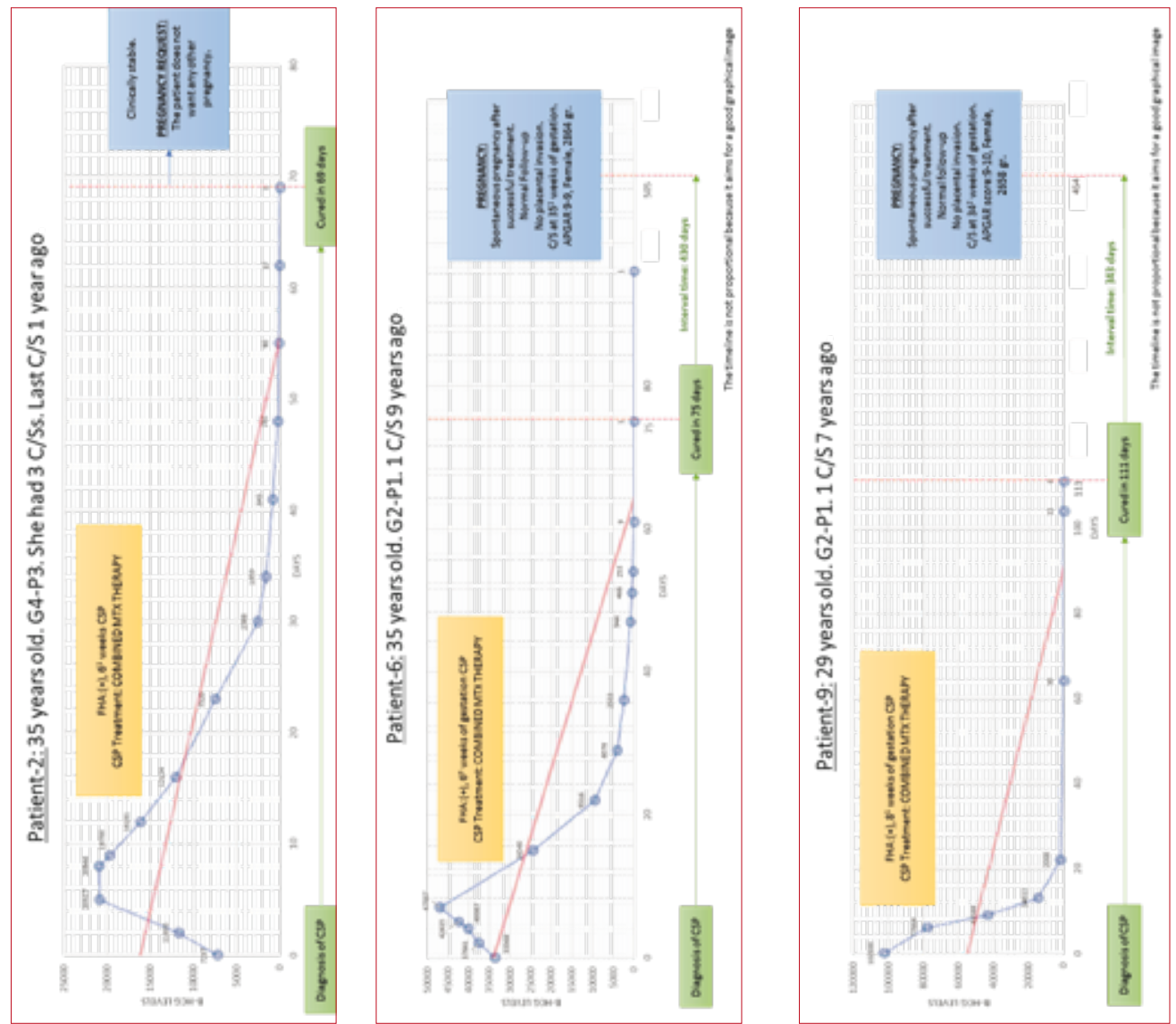

产

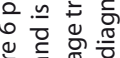

嵌

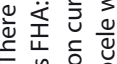

范

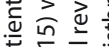

贾

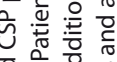

要

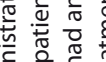

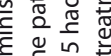

(1)

亭

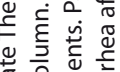

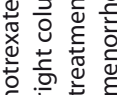

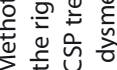

政

हो

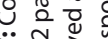

范 응 总

高哭 额

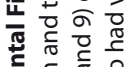

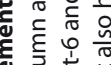

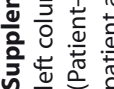

